\title{
The optimisation rule for investment in mining projects
}

\author{
Nam Foo ${ }^{1}$, Harry Bloch ${ }^{2}$ and Ruhul Salim ${ }^{3}$ \\ Department of Economics \\ Curtin University \\ Kent Street, Bentley \\ Perth, Western Australia, 6102
}

\begin{abstract}
Investment in mining projects involves significant uncertainty. Project investment is usually high risk, irreversible and challenged by major economic factors. Mining commodity prices in particular always show greater volatility than any other primary product industries. The variation of these prices is critical in the investment decision of whether the project should go ahead, be abandoned or be delayed. This paper examines the impact of mineral price uncertainty on mining investment decisions using examples of projects in the Asia-Pacific region. Applying the mean reversion (MR) model, the commodity trigger value for investment decisions in each project is determined in the context of operational flexibilities. The findings indicate it is sometimes better to wait for a more suitable time to invest.
\end{abstract}

JEL classifications: Q30, Q32, Q33

Keywords: Real options, Asia-Pacific, Investment decisions, Uncertainty, Critical value

\footnotetext{
${ }^{1}$ Department of Economics, Curtin University; Tel: +61403662915; email: nam.foo@ curtin.edu.au

${ }^{2}$ Emeritus Professor, Curtin University; Tel: +618-92662035; email: harry.bloch@cbs.curtin.edu.au

${ }^{3}$ Associate Professor, Curtin University; Tel: +618-92664577; email: ruhul.salim@cbs.curtin.edu.au
} 
[Type here]

\section{Introduction}

Investment in the resource industry has three important characteristics. First, mining investment is partially or completely irreversible and the initial cost of investment is at least partially sunk. Second, investment in mining projects involves uncertainty over future rewards. Third, mining project investment has some leeway with regard to timing with the mining investor able to delay investment to obtain more information about future investment conditions. These three characteristics interact to determine the optimal decision rules of investors in mining investment decision making.

When investments are irreversible and the economic environment is volatile, the option value of maintaining flexibility is high. The ability to delay is a powerful component of the strategy of mining investment. The irreversibility of investment creates exposure to losses in the highly volatile commodity market. The research question addressed here, through empirical analysis using examples from Asia-Pacific mining investment projects, is: How can mining companies use the strategy of deferral to decide the optimal timing for investment when commodity prices are volatile?

Mining commodity prices always show greater volatility than those of any other primary product industries. As a result of these uncertainties, finding the critical price at which it is optimal to invest in a project, is crucial. To address the research question identified above, the research applies the mean reversion (MR) model, using the commodity trigger value to determine investment decisions.

The rest of the paper proceeds as follows. Section 2 discusses background studies on mining investment in the Asia-Pacific region and also presents the primary role of the mining industry in the Asian Century for certain mineral-exporting Asia-Pacific countries. Section 3 reviews previous literature on mineral price uncertainty. Section 4 introduces the model used to forecast mineral prices under the optimisation investment rule, applying timing with flexibility. Section 5 describes the data collection and presents the results. Section 6 concludes.

\section{The mining industry and the Asian Century}

The Asia-Pacific region is one of the major mineral producers and consumers in the world (APEC Business Advisory Council, 2014). In world terms, the region contains substantial natural resources, including a wide variety of non-fuel mineral reserves, such as copper, gold, nickel, tin and many more (O'Callaghan and Vivoda, 2010). In 2013, for instance, the APEC economies accounted for approximately 76 percent of world copper reserves, 65 percent of 
world zinc reserves, 87 percent of world lead reserves and 48 percent of world nickel reserves (APEC, 2014). ${ }^{4}$

The Asia-Pacific region covers a diverse landscape enriched with mineral resources and it is one of the most influential economic zones in the world. Some advanced economies in this region, Australia in particular, are significantly affected by the Asian economy as a result of the region's growing demand for commodities. The mining industry can generate 60-90 percent of a country's foreign direct investment (FDI, 30-60 percent of total exports, 3-20 percent of total government revenues, 3-10 percent of total national income and 1-2 percent of total employment (International Council on Mining \& Metals, 2015) . In 2014, the Mining Contribution Index (MCI) (see Table 1) shows that a majority of the Asia-Pacific countries are dependent on the mineral resource industry as a major source of revenue to sustain their national economies.

In 2011, the Asia-Pacific region was regarded as being the strongest region in the world in terms of total project loan financing for the mining industry. For example, in Australia the total project loan finance figures for 2011 were US\$23.4 billion, the second highest total project loan in the world after India (Austrade, 2012). The increased demand for total project finance loans in the Asia-Pacific region can be attributed to the strong economic development in this region, particularly the strong demand for mineral resources in China and India.

\footnotetext{
${ }^{4}$ APEC has 21 members, which include Australia, Brunei Darussalam, Canada, Chile, the People's Republic of China, Hong Kong, Indonesia, Japan, the Republic of Korea, Malaysia, Mexico, New Zealand, Papua New Guinea, Peru, the Philippines, Russia, Singapore, Chinese Taipei, Thailand, the USA and Vietnam. The resource sector is one of the most important industries in APEC economies and this region accounts for a substantial share of world mineral resources.
} 
[Type here]

Table 1

Contribution of mining to national economies in the Asia-Pacific region.

\begin{tabular}{llll} 
Mining export & Total export & 2012 & 2014 \\
contribution & contribution & production & MCI \\
(2012) & (2012) & value (\% of & Score \\
& & GDP) & \\
\hline
\end{tabular}

\begin{tabular}{lllll}
\hline OECD members & & & & \\
Australia & $57.3 \%$ & $69.0 \%$ & $10.0 \%$ & 89.36 \\
Japan & $3.7 \%$ & $5.4 \%$ & $0.0 \%$ & 42.09 \\
New Zealand & $4.7 \%$ & $9.5 \%$ & $0.9 \%$ & 40.76 \\
East Asian economies & & & & \\
China & & & & \\
Hong Kong SAR & $1.5 \%$ & $2.9 \%$ & $6.1 \%$ & 39.54 \\
South Korea & $14.9 \%$ & $15.2 \%$ & $0.0 \%$ & 53.53 \\
South-East Asian economies & $2.7 \%$ & $13.2 \%$ & $0.1 \%$ & 35.30 \\
Indonesia & & & & \\
Malaysia & $20.1 \%$ & $40.7 \%$ & $6.3 \%$ & 78.46 \\
Philippines & $2.6 \%$ & $23.0 \%$ & $0.6 \%$ & 45.78 \\
Singapore & $6.3 \%$ & $8.5 \%$ & $2.5 \%$ & 57.04 \\
Thailand & $1.8 \%$ & $20.3 \%$ & $0.0 \%$ & 16.73 \\
Pacific Island countries6 & $5.2 \%$ & $11.7 \%$ & $0.7 \%$ & 55.16 \\
Fiji & & & & \\
Papua New Guinea & $9.3 \%$ & $34.1 \%$ & $1.9 \%$ & 71.94 \\
Solomon Islands & $51.3 \%$ & $68.5 \%$ & $26.1 \%$ & 88.54 \\
Tonga & $15.5 \%$ & $15.6 \%$ & $10.1 \%$ & 83.93 \\
USA & $7.5 \%$ & $7.5 \%$ & $0.0 \%$ & 47.02 \\
\hline Soure: & $7.7 \%$ & $15.6 \%$ & $0.8 \%$ & 60.88 \\
\hline
\end{tabular}

Source: International Council on Mining and Metals (2015); Minerals Council of Australia (2014)

\section{Literature review}

Economic viability in today's mining industry is highly dependent on sound company planning and management. A key decision support system, which mining firms can successfully apply to resolve their investment planning and management problems, is optimisation. Optimisation techniques include ore-body or reserve estimation, the design of optimal pits, optimal production planning, the determination of optimal mine operation layouts, the development of machinery maintenance and replacement policies, the implementation of

\footnotetext{
5 Taiwan is included in China's MCI.

${ }^{6}$ These four Pacific Island countries are the major exporters of mineral resources. The contributions of the mining industry to national economies in other Pacific island countries, such as the Marshall Islands, Samoa, Timor-Leste and Vanuatu, only comprise zero to 20 percent of their economies. The table, therefore, only shows those countries in which the mining industry is the major source of income that sustains national economic growth.
} 
an efficient mine site redevelopment programme, determining the best choice of machinery (e.g. trucks and loaders for mining operations) and the design and efficient operation of matters related to transportation and the logistics network to support mining operations (Caccetta, 2010, p. 547).

The use of optimisation decision support models in large-scale mining projects has been studied extensively, in the copper resource sector by Mondschein and Schilkrut (1997), Caldentey and Mondschein (2003) and Caldentey et al. (2007). Epstein et al. (1999) examines techniques used in the renewable forestry industry, while their use in the oil industry is examined by Baker and Lasdon (1985), Dyer et al. (1990) and Gibson and Schwartz (1990) .

The advantage of using these optimisation decision techniques is that mining firms are able to evaluate their investment projects by choosing those that have short-term and long-term profitability. Caldentey et al. (2007) point out that most of these models use state variables, such as commodity market prices and mineral demand, as independent variables to determine mining firms' investment decisions. Within optimisation modelling, real option valuation (ROV) is one of the most powerful financial techniques, assessing all information by incorporating flexibility to evaluate large-scale mining projects.

When dealing with uncertainty in the real options model, Schwartz and Smith (2000) show the significant role the stochastic model of commodity prices plays in evaluating mining project investment. Price variables in a stochastic model evolve in either discrete or continuous time periods in an unpredictable way. Stochastic price behaviour can be estimated using either a geometric Brownian motion (GBM) (Brennan and Schwartz, 1985; McDonald and Siegel, 1986), especially in the short term, or using a mean reversion (MR) model (Ozorio et al., 2013) in the long term. Monte Carlo simulation (MCS) is another stochastic approach used in forecasting mineral prices.

In early studies using stochastic models in relation to price risks, researchers tended to assume that commodity prices followed a "random walk" (described by GBM). ${ }^{7}$ GBM is a process that does not follow any simple deterministic rule, such as "a commodity price will increase by $X$ percent every year". The path of stock prices in the share market is often used as an example of a GBM process because the path is purely random and cannot be predicted. When applying the GBM model, it is expected $t$ increases in commodity prices in one time period cause smaller increases for all future forecasted commodity prices.

\footnotetext{
${ }^{7}$ The GBM model was first used in the Black-Scholes (B-S) option pricing formula (Black and Scholes, 1973) for evaluating stock price uncertainty.
} 
[Type here]

Although GBM is one of the common stochastic models for mineral price modelling, several studies have also examined using the MR price model in evaluating commodity price risks in the mining industry (e.g. Laughton and Jacoby, 1993; Cortazar and Schwartz, 1994; Dixit and Pindyck, 1994; Smith and McCardle, 1999). In the long term, for most commodity prices, there is some mean reversion in prices. However, there is also uncertainty about the market commodity price equilibrium to which the commodity price reverts when applying the meanreverting price model.

MCS is another approach to forecast commodity prices when commodity markets are highly volatile and uncertain. MCS is applied to valuing options through finite difference and binomial lattices models. The main applications of this method are risk analysis, risk quantification, sensitivity analysis and predictions, which enable mining investors to capture the impact of the uncertain variables that could most substantially affect their investment decisions.

\section{The model}

\subsection{Forecasting mineral prices}

Stochastic models of mineral prices in the resource sector play an important role when evaluating commodity-related mining projects (Schwartz and Smith, 2000). Most common among studies using stochastic models to evaluate mining projects is assuming commodity prices follow a "random walk" as described by GBM (Brennan and Schwartz, 1985; Paddock et al., 1988; Smith and McCardle, 1999). However, many researchers believe mineral prices should, to some extent, be related to long-term marginal production costs (Dixit and Pindyck, 1994). In other words, in the short term, commodity prices might fluctuate randomly up and down in response to economic uncertainties, such as wars or civil revolutions, or in response to changes in government mineral policies, but in the long term commodity prices are drawn back towards the marginal cost of production. Thus, a mean reversion process is used for modelling commodity prices in the applications in this paper.

Schwartz's (1997) one-factor geometric mean reversion (GMR) model is an example of a model able to capture pricing uncertainties when applying ROV. This model is particularly useful when modelling a spot price process forecast for periods of greater than 30 years. Many studies that support the idea of commodity prices following a mean reversion process and revert to an equilibrium level in the long run (Gibson and Schwartz, 1990; Dixit and Pindyck, 1994; Schwartz, 1997; Hahn and Dyer, 2008; Aleksandrov and Espinoza, 2009).

The model in this study assumes the mining project under consideration produces a single mineral commodity and spot prices follow the stochastic process written as follows:

$$
d S_{t}=\kappa\left(\mu-\ln S_{t}\right) S_{t} d t+\sigma S_{t} d Z_{t}
$$


where $\mathrm{K}$ is the speed of reversion, $\mu$ is the level of mean reversion, $\sigma$ is the volatility of commodity prices and $Z_{t}$ is the increment of a Wiener process. Defining $X_{t}=\ln S_{t}$ and applying Ito's lemma, the log price process follows the Ornstein-Uhlenbeck stochastic process, also called the arithmetic MR process, which can be written as follows:

$$
d X_{t}=\kappa\left(\alpha-X_{t}\right) d t+\sigma d W_{t}
$$

where

$$
\alpha=\mu-\frac{\sigma^{2}}{2 \kappa}
$$

Note that the expected change in $X$ in Eq. (2) depends on the difference $\alpha-X_{t}$. In other words, the mean-reverting process is based on $\alpha$. If $X$ is greater than $\alpha$, the expected value of $X$ falls. If $X$ is less than $\alpha$, the expected value of $X$ rises.

Eq. (2) is the continuous time version of the first-order autoregressive (AR1) process in discrete time. The equation is particularly useful in the limiting case when $d t \rightarrow 0$. The AR1 process in discrete time is written as follows:

$$
X_{t}-X_{t-1}=\bar{X}\left(1-e^{-\kappa}\right)+\left(e^{-\kappa}-1\right) X_{t-1}+\epsilon_{t}
$$

where unit root tests are used to test econometrically for mean reversion, which requires $k>$ 0 .

\subsection{Real options valuation (ROV) - binomial decision tree analysis}

The standard net present value (NPV) rule is appropriate for use only with the absence of uncertainty (Brennan and Trigeorgis, 2000). Under the NPV or discounted cash flow approach, mining investment projects are carried out if, and only if, the discounted present value of project net revenue is greater than the investment cost. Otherwise, investment in mining projects is withheld.

Numerous studies have shown that there are limitations to static discounted cash flows (Myers, 2001; Cobb and Charnes, 2007; Guthrie, 2009; Foo, 2015). Moyen et al. (1996, p. 63) state "many practitioners claim to be dissatisfied with traditional net present value techniques. In particular, it is often found that such calculations undervalue mining assets". The discounted cash flow ignores mining firms' flexibility in responding when market conditions deviate from their expectations.

The shortcomings of the conventional discounted cash flow method, with its lack of recognition of managerial flexibility, have induced a search for other valuation methods that will enable mining firms to make project investment decisions with flexibility when market uncertainty occurs (Dixit and Pindyck, 1995). The real option valuation (ROV) approach is one 
of the primary enhanced decision-making frameworks, which adds value by taking advantage of flexibility (Lander and Pinches, 1998).

Applying the ROV framework to evaluate mining investment projects has three major advantages. First, it considers all the flexibilities that the investment project might have. Second, it uses all the information available for market prices to obtain the best possible investment decision outcome when such prices exist. Third, it allows the use of powerful strategies, such as the option to delay, developed in contingent claims analysis to determine both the project value and the optimal operating policy (Schwartz and Trigeorgis, 2001).

Brennan and Schwartz (1985) introduces the use of ROV in empirical research in natural resource industries. The empirical evidence in Brennan and Schwartz shows support for the use of real option theory to capture the value in terms of being able to delay investment until the optimal time in mining when future movements in commodity prices are uncertain. Many leading mining and oil and gas companies use ROV in their project development (Sick, 1995).

McDonald and Siegel (1986) consider the appropriate timing for mining investors to pay a sunk cost $I$ in return for expected future project cash flows the value of which is $V$. The value of $V$ represents a discounted expected cash flow at time $t$ and follows GBM:

$$
d V=\alpha V d t+\sigma V d z
$$

where $d z$ is a standard Wiener process. When undertaking the investment decision, the mining firm knows the present value of the project, but the expected future values are lognormally distributed with variance that grows linearly with the time in the future.

Dixit and Pindyck (1994) examine the optimal timing of an irreversible mining investment project, beginning with the initial mining investment project in which $V$ follows Eq. (5). The mining firm receives the payoff value at time $t$, which is $V_{t}-I$. The value of the option to invest represented by $F(V)$ is found by maximising the expected present value:

$$
F(V)=\max \left[E\left[\left(V_{t}-I\right)\right] e^{-\rho t}\right]
$$

where $\rho$ represents the discount rate and the evolution of $V_{t}$ is determined by Eq. (5).

The condition $\alpha<\rho$ is applied as otherwise the integral in Eq. (5) can be indefinitely large when $t$ is large. In the stochastic case, with $\sigma>0$, the mining firm seeks to determine at which point it is optimal to invest $I$. This is done by finding a critical value $V^{*}$ such that the investment decision takes place once $V \geq V^{*}$. Examples of the process are provided in the next section. 
[Type here]

\section{Data collection and empirical outcomes}

To conduct an empirical analysis of mineral price uncertainties, the study uses data from online secondary data resources. The data are primarily from Index Mundi, the World Bank, the International Monetary Fund (IMF) and government websites, such as those of central banks for interest rates.

The analysis of mineral price simulations uses @ Risk software and Syncopation software DPL 8 decision programming language. The commodity price data for forecasting are from the World Bank. The coal price data are collected for the period from early January 1970 to August 2014 and the gold price data from January 1960 until August 2014. In determining the optimisation investment rule, for the commodity prices @ Risk software is first used to simulate the forecasting of future mineral spot prices, then DPL 8 is applied to solve the ROV.

\subsection{Forecasting commodity prices}

Based on historical data over 50-year periods available from the World Bank, the forecasted results show that the value of precious metals such as gold is continuing to rise. However, there is significant volatility in coal prices due to the demand and supply of coal in the world market. The forecast shows that the coal price is likely to ease after 2015. These average monthly coal and gold prices can then be simulated using @Risk software MCS with 5,000 iterations. Fig. 1 and Fig. 2 show the simulation of these two prices. The complete commodity price simulation is discussed in Appendix 1a.

Using MCS with 5,000 iterations, the gold price simulation shows that for the gold mining project, there is a five percent chance the gold price falls below US $\$ 1,064$ per ounce and a five percent chance the gold price goes above US\$1,686 per ounce. For the coal mining project, the simulation shows that with a 90 percentile target, the coal price will have a five percent chance of falling below US $\$ 42.90$ per metric ton and a five percent chance of going above US $\$ 98.00$ per metric ton. 


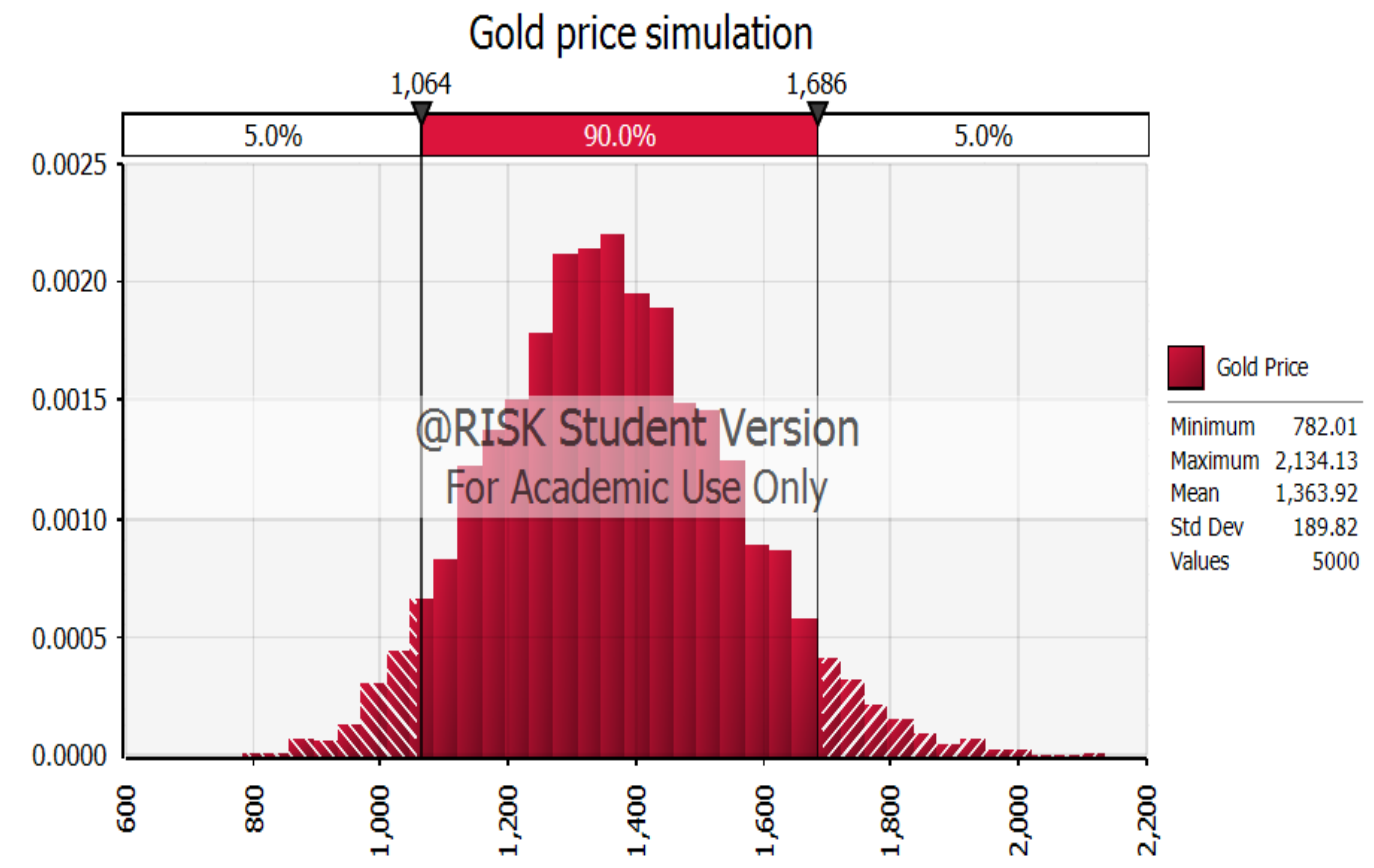

Fig. 1. Gold price simulation.

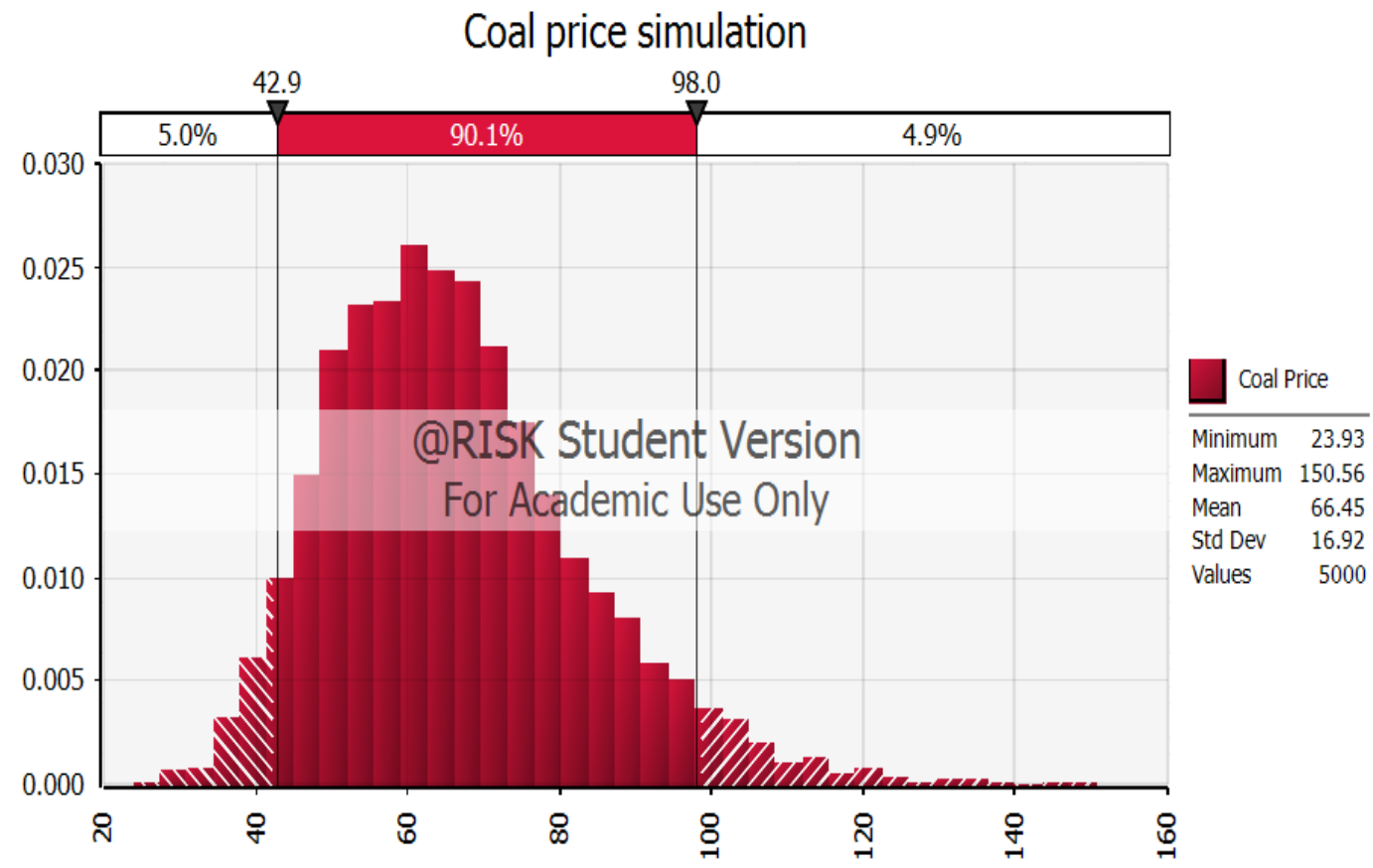

Fig. 2. Coal price simulation. 
[Type here]

The key point of running this simulation is to obtain the forecasted gold and coal prices, which are then used in determining the critical value, $V^{*}$, for undertaking investment in illustrative examples of a mining project for gold and another for coal. Determination the critical value follows the procedure outlined in Dixit and Pindyck (1994), finding the value of the option to invest and the investment rule for a mining investment.

\subsection{The empirical evidence using binomial approach}

Option pricing is extremely sensitive to the level of volatility of the project's NPV. Therefore, an important feature in conducting this empirical analysis is to examine an optimisation framework for the timing of investment decisions; by deferring an investment project rather than investing immediately, the mining firm may have the opportunity to achieve better NPV. Fig. 3 presents the set-up of an ROV lognormal binomial decision model for a hypothetical investment in gold mining over a five-year period, which shows the impact of the volatility of mineral prices on NPV. 
[Type here]

Gold

Price 1

Exercise1?

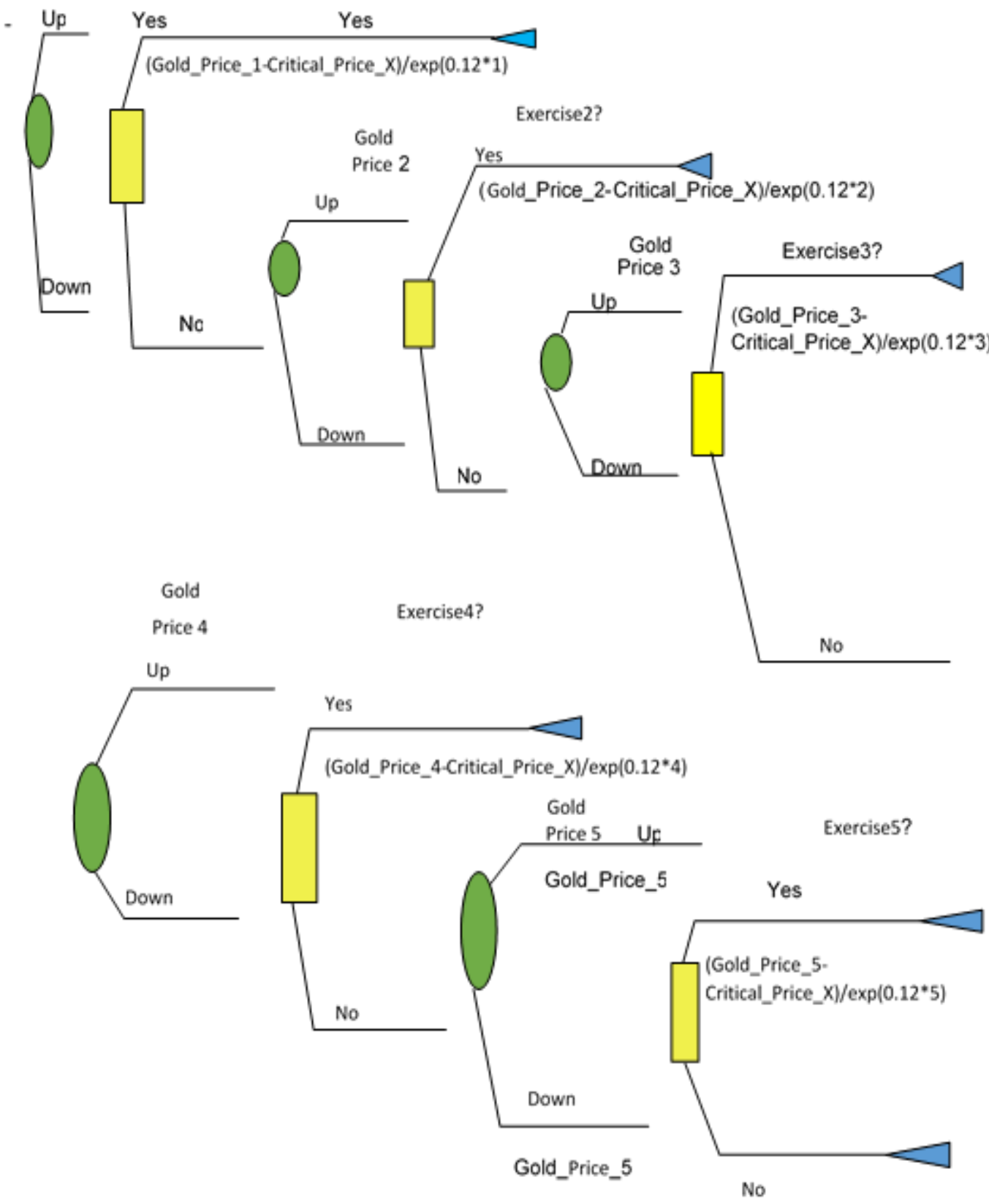

Fig. 3. Gold price simulations using American call options. 
[Type here]

Using DPL 8, the study follows the steps applied by Tan et al. (2009) to evaluate a mining project using the binomial model. ${ }^{8}$ The first three steps are exactly the same as the set-up applied in the traditional DCF model: 1) identify the decision variables; 2) build the deterministic DCF model; 3) specify the distributions for the uncertain variables using a separate Excel sheet. The next five steps are conducted as follows: 4) calculate the expected NPV of the mining project without options valuation at $t=0$ using a DCF analysis; 5) obtain the cash flow payout rates for each period in $u$ and $d$ states using an exponential function of the cash flow return volatility multiplied by the square root of time steps or stepping time $(\delta t) ; 6)$ estimate the volatility $(\sigma)$ of the project returns using the logarithmic stock prices returns approach; 7) calculate the parameters of the binomial approximation, $u, d, p$ for the GBM; 8) set up the binomial lattice using DPL; 9) solve the option by forming decision nodes in the model using the risk-free rate. ${ }^{9}$

Fig. 4 shows the binomial decision tree model for the state variables using the forecasted gold price in the American call option. An advantage of using an American-style call option is that it enables the mining investor to exercise the option prior to the expiration date. As a result, a model is established in which exercising an option can be executed at any time prior to maturity. After the price is revealed in each period, the investor decides whether to invest or continue to hold the option.

\footnotetext{
${ }^{8}$ DPL8 is one of the software products used for the system dynamic model to solve the option problem for the project with uncertainties.

${ }^{9}$ Volatility estimation in mining project valuation is discussed in Appendix $1 b$.
} 


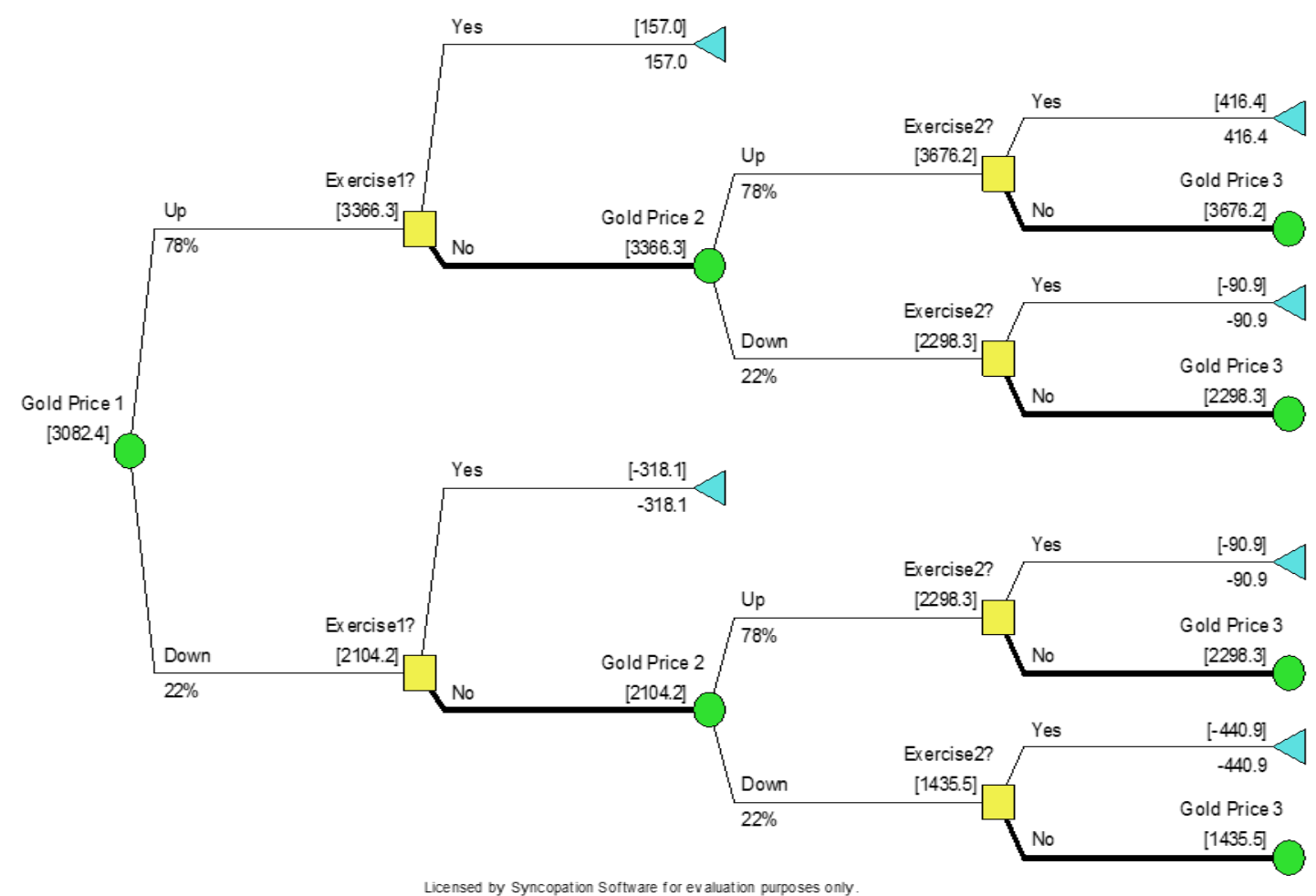

Fig. 4. Option values of the Mengapur gold mining project in Malaysia using the American Call option. ${ }^{10}$

In terms of whether or not to exercise the option, the project's value is dependent on the objective function. In this case, the objective function is Gold_Price_1Critical_Price_X/exp $(0.12 * 1) .{ }^{11}$ Gold_Price_1 is initially set at $\$ 1,434.43$ per ounce. As mentioned in the previous section, an investment rule is constructed for the project investment based on intrinsic value or the so-called critical price. In the objective function, Critical_Price_X is set to $\$ 1,550$ per ounce. This critical price is the intrinsic value that the mining firm is able to use to make the investment decision. By adopting this investment rule, the mining investor can decide whether or not to invest.

\footnotetext{
${ }^{10}$ There are 11 levels in the model. Thus, it has been necessary to reduce the model size by showing only 5 levels of this analysis in the study.

${ }^{11}$ The binomial decision tree model for coal price is not shown in this section. The coal price model set-up is similar to the gold price model shown in Fig. 4.
} 


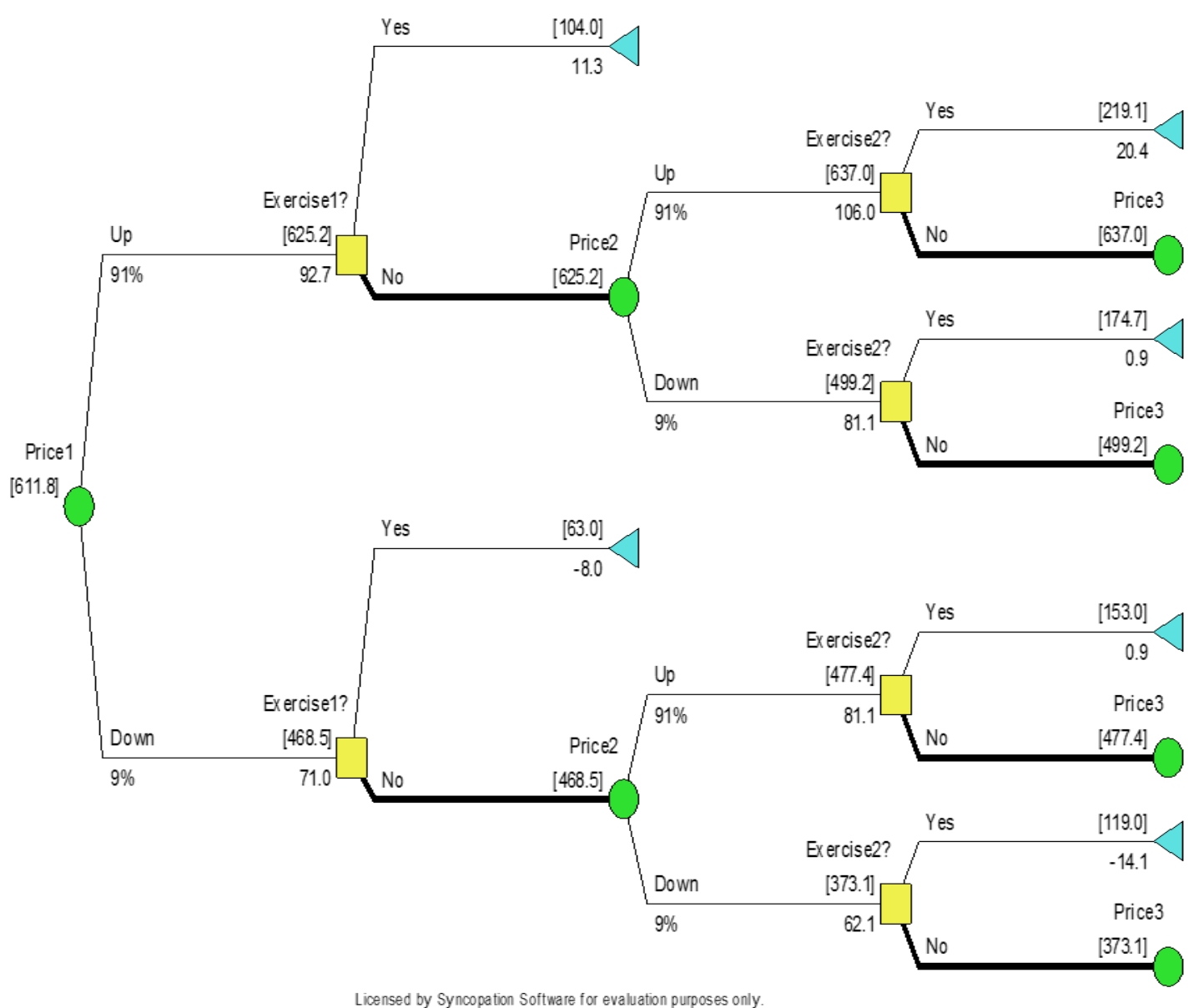

Fig. 5. Option values of the Daunia coal mining project in Australia using the American Call option.

In the binomial decision tree model for the coal mining project, Fig. 5 shows that the coal mining investor should defer project investment until the expiry of the time option value. If the coal price is above $\$ 400$ per metric ton, investment at the end of a five-year period is optimal. The project should be abandoned entirely if coal price has dropped below $\$ 390$ per metric ton. ${ }^{12}$

The key point in summarising the outcomes shown in Fig. 4 and Fig. 5 is that timing flexibility is a useful strategy to tackle highly volatile variables such as mineral prices when considering high-risk mining investment projects. Understanding timing flexibility is a critical point. The findings of Auger and Guzman (2010) are worth noting. These authors state that in their sample "fewer than half of decisions were made at the right time - i.e. low price periods" (p.249). However, capturing the right timing can be a difficult task because of the unpredictable economic climate.

\footnotetext{
${ }^{12}$ One interesting point of this outcome is that it is better to wait to execute the option value until the time of expiration. From a practical perspective, it is not advisable to exercise an option early. This is because the time value inherent in the option value will be lost if the option is exercised early.
} 
[Type here]

\section{Conclusion}

Adopting a strategy of flexibility by understanding optimal timing is one of the keys to success in today's extremely volatile investment climate. Applying the optimisation investment rule using a powerful financial technique such as ROV binomial decision analysis can enhance returns from investment projects in the natural resource, oil and gas industries.

The commodity price is usually the most volatile variable in decision making concerning mining project investments. The uncertainty of mineral prices is of paramount importance in many natural resource industries, in which these prices tend to swing approximately 25-40 percent per annum (Brennan and Schwartz, 1985). Adopting the option to defer mining investment is found to be an optimal strategy in the current economic climate, which is significantly volatile and uncertain. By applying this approach using the ROV method to examples of gold and coal mining projects in the Asia-Pacific region, we find that using the option to defer offers an avenue for mining investors to take advantage of the resolution of uncertainty concerning commodity prices.

In this study, using a five-year period for only two illustrative projects means it is difficult to make generalisations about the strategy of flexibility in timing for mining investments. Also, variability in other elements affecting returns, such as production costs, labour costs and other capital expenditures, has not been included. These variables can significantly affect the investment decision, a matter that is left for future research. Future research could also be extended to focus more on timing flexibility using with agricultural investment activities.

\section{References}

Aleksandrov, N., and R. Espinoza. 2009. "Optimal Oil Etraction as a Multiple Real Option." Oxford-Man Institute of Quantitative Finance. University of Oxford. Oxford.

APEC Business Advisory Council. 2014. 8th Mining Task Force Meeting APEC. Accessed 20 August http://mddb.apec.org/Documents/2014/MTF/MTF/14_mtf8_019.pdf.

Auger, F., and J. Guzman. 2010. "How Rational Are Investment Decisions in the Copper Industry?" Resources Policy 35 (4): 292-300.

Austrade. 2012. "Australia - Corporate Finance Activities Remain Strong." edited by Australia Trade Commission, Canberra: Australian Government.

Baker, T.E., and L.S. Lasdon. 1985. "Succesive Linear Programming at Exxon." Management Science 31 (3): 264-274.

Black, F., and M Scholes. 1973. "The Pricing of Options and Corporate Liabilities " Journal of Political Economy 81 (3): 133-155. 
[Type here]

Brennan, M.J., and E.S. Schwartz. 1985. "Evaluating Natural Resource Investments." The Journal of Business 58 (2): 135-157.

Brennan, M.J., and L Trigeorgis. 2000. "Real Options: Development and New Contributions." In Project Flexibility, Agency, and Competition, eds M.J. Brennan and L Trigeorgis, 110. New York Oxford University Press.

Caccetta, L. 2010. "Application of Optimisation Techniques in Open Pit Mining." In Handbook of Operations Research in Natural Resources, eds A. Weintraub, C. Romero, T. Bjorndal and R. Epstein, 547-559. Santiago: Springer Science+Business Media, 2010. pp.547-559.

Caldentey, R., R. Epstein, and D. Saure. 2007. "Optimal Exploitation of a Nonrenewable Resource." In mimeo., edited by New York University, New York: New York University.

Caldentey, R., and S.V. Mondschein. 2003. "Policy Model for Pollution Control in the Copper Industry, Including a Model for the Sulfuric Acid Market " Operation Research 51 (1): $1-16$.

Cobb, B.R., and J.M. Charnes. 2007. "Real Options Valuation" Proceedings of the 2007 Winter Simulation Conference, Washington D.C.: IEEE.

Cortazar, G., and E.S. Schwartz. 1994. "The Valuation of Commodity-Cntingent Claims." The Journal of Derivatives 1: 27-39.

Dixit, A. K., and R. S. Pindyck. 1994. Investment under Uncertainty. New Jersey: Princeton University Press.

. 1995. "The Options Approach to Capital Investment." Havard Business Review MayJune: $105-115$.

Dyer, J. S., R. N. Lund, J. B. Larsen, V. Kumar, and R. P. Leone. 1990. "A Decision Support System for Prioritising Oil and Gas Exploration Activities." Operations Research 38 (3): 386-396.

Epstein, R., R. Morales, J. Seron, and A. Weintraub. 1999. "Use of or Systems in the Chilean Forest Industries." Interfaces 29 (1): 7-29.

Foo, N. 2015. "Assessing Investment Strategies in Mining Projects in the Asia-Pacific Region." Department of Economics, Curtin University, Perth.

Gibson, R., and E. S. Schwartz. 1990. "Stochastic Convenience Yield and the Pricing of Oil Contingent Claims." The Journal of Finance 45 (3): 959-976.

Guthrie, G. 2009. Real Options in Theory and Practice. New York: Oxford University Press.

Hahn, W. J., and J. S. Dyer. 2008. "Discrete Time Modeling of Mean-Reverting Stochastic Processes for Real Option Valuation." European Journal of Operational Research 184: 534-548. 
[Type here]

IndexMundi. 2013. Historical Commodities Data. IndexMundi. Accessed 6-9, http://www.indexmundi.com/.

International Council on Mining \& Metals. 2015. The Role of Mining in National Economies (2nd Edition). ICMM. Accessed 15 March, http://www.icmm.com/document/7950.

Lander, D.M., and G.E. Pinches. 1998. "Challenges to the Practical Implementation of Modeling and Valuing Real Options." The Quarterly Review of Economics and Finance 38 (Special Issue): 537-567.

Laughton, D., and H. D. Jacoby. 1993. "Reversion, Timing Options, and Long-Term Decision Making." Financial Management 22 (3): 225-240.

McDonald, R., and D Siegel. 1986. "The Value of Waiting to Invest." The Quarterly Journal of Economics 101 (4): 707-727.

Minerals Council of Australia. 2014. "Joint Parliament Inquiry into the Role of the Private Sector in Promoting Economic Growth and Reducing Poverty in the Indo-Pacific Region." In The role of the private sector in promoting economic growth and reducing poverty in the Indo-Pacific region Submission 114, Melbourne.

Miranda, O., and L. E. Brandao. 2013. "A Real Option Model to Value an Exploration Mining Project: An Application." School of Business. Pontificia Universidade Catolica do Rio de Janeiro. Rio de Janeiro.

Modirroosta, M. 2013. "A Decomposition Analysis of Base Metal Prices: Comparing the Effect of Detrending Methods on Trend Identification and Cyclical Components." School of Business and Economics Michigan Technological University, Michigan.

Mondschein, S.V., and A. Schilkrut. 1997. "Optimal Investment Policies for Polluction Control in the Copper Industry." Interfaces 27 (6): 69-87.

Moyen, N., M.E. Slade, and R Uppal. 1996. "Valuing Risk and Flexibility: A Comparison of Methods." Resources Policy 22 (1/2): 63-74.

Myers, S. C. 2001. "Finance Theory and Financial Strategy." In Real Options and Investment under Uncertainty: Classical Readings and Recent Contribution, eds E.S. Schwartz and L Trigeorgis, 19-32. Cambridge: The MIT Press. pp.19-32.

O'Callaghan, T \& Vivoda, V. 2010. "Regulatory Regimes, Mining Investment and Risk in the Asia-Pacific Region: Critical Evaluation and Policy Recommendations." In Paper presented at the 51st International Studies Association annual convention, New Orleans, 19 February.

Ozorio, L.D.M., T.K.N. Baidya, C.d.L. Bastian-Pinto, and L.E. Brandao. 2013. "Investment Decision in Integrated Steel Plants under Uncertainty." International Review of Financial Analysis 27: 55-64. doi: http://dx.doi.org/10.1016/j.irfa.2012.06.003. 
[Type here]

Paddock, J.L., D.R. Siegel, and J.L. Smith. 1988. "Option Valuation of Claims on Real Assets: The Case of Offshore Petroleum Leases " The Quarterly Journal of Economics 103 (3): 479-508.

Schwartz, E.S. 1997. "The Stochastic Behaviour of Commodity Prices: Implications for Valuation and Hedging." The Journal of Finance 52 (3): 923-973.

Schwartz, E.S., and J.E. Smith. 2000. "Short-Term Variations and Long-Term Dynamics in Commodity Prices." Management Science 46 (7): 893-911.

Schwartz, E.S., and L. Trigeorgis. 2001. "Real Options and Investment under Uncertainty: An Overview." In Real Options and Investment under Uncertainty: Classical Readings and Recent Contributions, eds E.S. Schwartz and L. trigeorgis, 1-16. Cambridge, Massachusetts: MIT. pp.1-16.

Shafiee, S. 2010. "Integrating Econometrics Models in Real Option Valuation of Coal Mining Projects." School of Mechanical \& Mining Engineering, The University of Queensland.

Sick, G. 1995. "Real Options." In Handbooks in or \& Ms, ed. R. et.al. Jarrow. Elsevier Science B.V.

Smith, J. E., and K. F. Mccardle. 1999. "Options in the Real World: Lessons Learned in Evaluating Oil and Gas Investments." Operations Research 47 (1): 1-15.

Tan, B., E Anderson, G.,, J. S. Dyer, and G. G. Parker. 2009. "Using Binomial Decision Trees and Real Options Theory to Evaluate System Dynamics Models of Risky Projects." System Dynamics Review: 1-15.

The World Bank. 2015. "Databank." edited by The World Bank., Washington.

Tilton, J. 2003. On Borrowed Time? Assessing the Threat of Mineral Depletion: RFF Press. 
[Type here]

\section{Appendices}

\section{Appendix 1: Commodity price simulation}

Mining commodity prices show greater volatility than any other primary product industry. The variation in these prices is considered to be a reflection of resource availability (Tilton, 2003). In the resource industry, mining production decisions and the rate of mineral production are highly dependent on commodity prices (Modirroosta, 2013).

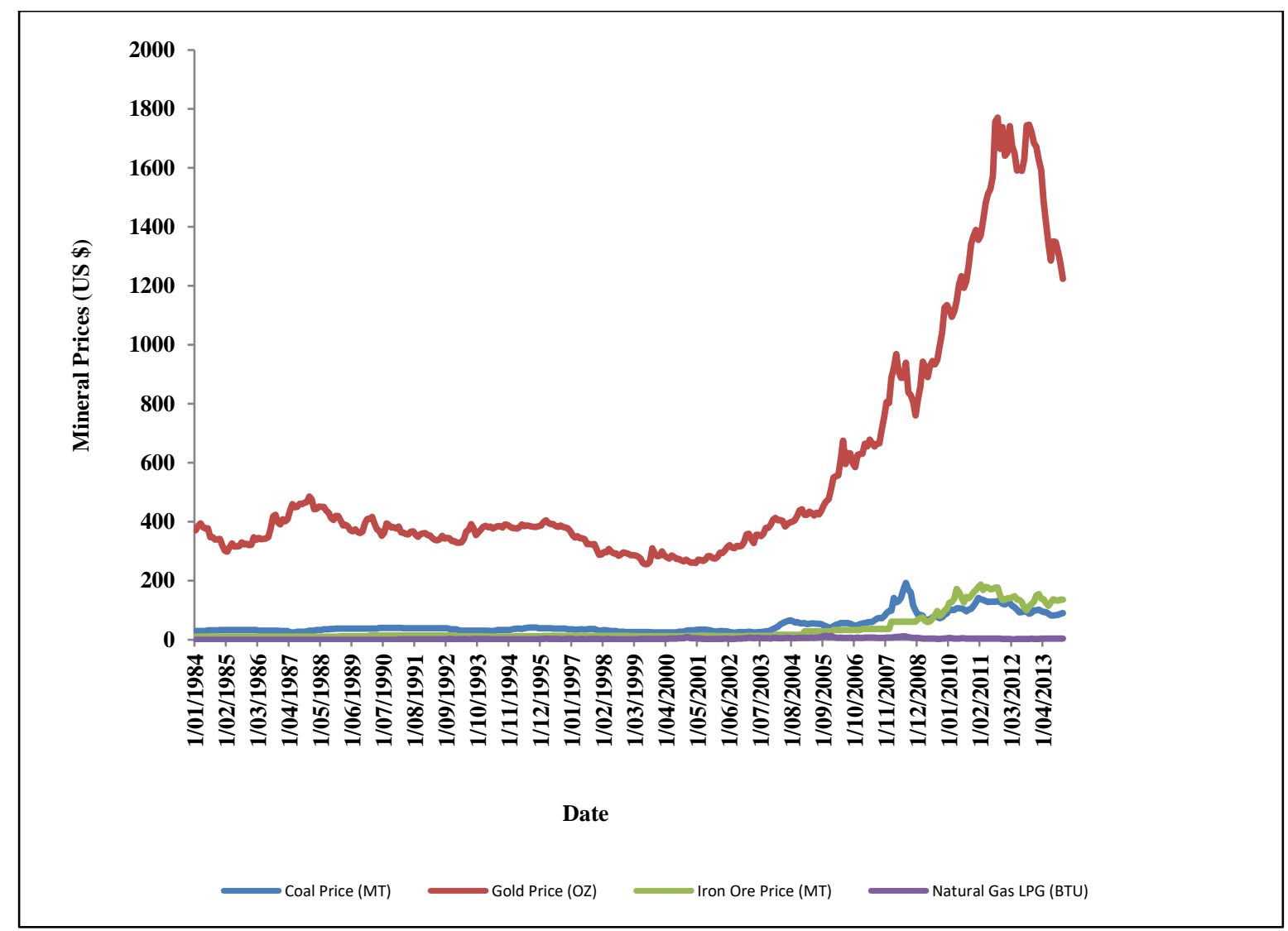

Source: IndexMundi (2014)

Fig. A1. The historical trend of mineral and energy prices.

Figure A1 indicates the fluctuation in the historical prices for commodities and energy prices over a 30 -year period. 
[Type here]

Table A1

Monthly average projected prices for gold.

\begin{tabular}{lc}
\hline Month & USD/ounce \\
\hline Sept 2014 & 1294.99 \\
Oct 2014 & 1297.89 \\
Nov 2014 & 1301.39 \\
Dec 2014 & 1305.00 \\
Jan 2015 & 1308.64 \\
Feb 2015 & 1312.29 \\
Mar 2015 & 1315.95 \\
Apr 2015 & 1319.60 \\
May 2015 & 1323.27 \\
Jun 2015 & 1326.93 \\
Jul 2015 & 1330.59 \\
Aug 2015 & 1334.27 \\
Sept 2015 & 1337.93 \\
Oct 2015 & 1341.61 \\
Nov 2015 & 1345.29 \\
Dec 2015 & 1348.98 \\
Jan 2016 & 1352.65 \\
Feb 2016 & 1356.35 \\
Mar 2016 & 1360.04 \\
Apr 2016 & 1363.74 \\
May 2016 & 1367.44 \\
Jun 2016 & 1371.14 \\
Jul 2016 & 1374.84 \\
Aug 2016 & 1378.55 \\
\hline
\end{tabular}

Table A2

Monthly average projected prices for coal.

\begin{tabular}{lc}
\hline Month & USD/metric ton \\
\hline Sept 2014 & 68.09 \\
Oct 2014 & 70.58 \\
Nov 2014 & 69.92 \\
Dec 2014 & 70.65 \\
Jan 2015 & 74.40 \\
Feb 2015 & 75.75 \\
Mar 2015 & 75.91 \\
Apr 2015 & 73.79 \\
May 2015 & 74.89 \\
Jun 2015 & 73.53 \\
Jul 2015 & 72.07 \\
Aug 2015 & 70.77 \\
Sept 2015 & 69.98 \\
Oct 2015 & 68.53 \\
Nov 2015 & 66.44 \\
Dec 2015 & 66.67 \\
Jan 2016 & 67.51 \\
Feb 2016 & 68.29 \\
Mar 2016 & 68.19 \\
Apr 2016 & 68.11 \\
May 2016 & 68.29 \\
Jun 2016 & 68.00 \\
Jul 2016 & 68.37 \\
Aug 2016 & 68.23 \\
\hline
\end{tabular}


[Type here]

The commodity price data for forecasting are from the World Bank. The coal price data are collected for the period from early January 1970 to August 2014 and the gold price data from January 1960 to August 2014. Selecting an appropriate stochastic model is a crucial step in the process of evaluating mining investment (Miranda and Brandao, 2013). The stochastic process has a direct impact on the behaviour of the ROV, which can affect decision making as a whole. This study employs a 50-year period to forecast commodity prices as this period is deemed long enough for prices to revert to a long-term average price (Ozorio et al., 2013).

Based on historical data over a fifty-year period available from the World Bank, Tables A1 and A2 show the average monthly movement of coal and gold prices. The forecasted results show that the value of gold is continuing to rise. However, there is significant volatility in coal prices and the forecast shows that coal price is likely to ease after 2015. 